\title{
Deformation Behaviour of Geogrid Reinforced Soil Walls under Strip Loading
}

\author{
Seema L. Gawali ${ }^{1}$ \\ Civil Engineering \\ Jawaharlal Nehru Engineering college \\ Aurangabad, Maharashtra, India
}

\author{
L. G. Kalurkar ${ }^{2}$ \\ Civil Engineering \\ Jawaharlal Nehru Engineering college \\ Aurangabad, Maharashtra, India
}

\begin{abstract}
Static response of geogrid reinforced soil walls with wrap around facing resting on firm foundation to the externally imposed strip load is presented in this study. A series of small-scale experimental tests was performed on the model geogrid reinforced soil walls with geofoam inclusion varying the placement position of strip load over reinforced zone to backfill. Experimental analysis was performed in a prefabricated MS(mild steel) strong box. A thick glass panel was fixed on the front side of the strong box so as to capture movements in experimental models. Wrap around facing technique was used to represent the flexible facing conditions. Reinforcement spacing and reinforcement length was adopted to be $0.084 \mathrm{H}$ (Height) and $0.7 H(H e i g h t)$ respectively. Surcharge loading was applied on each model in the form of $0.05 \mathrm{~m}$ wide strip load at $0.5 \mathrm{~L}_{\mathrm{r}}$ (length of reinforcement)and at $1.78 \mathrm{~L}_{\mathrm{r}}$ (length of reinforcement)from the crest of the wall. Each model test was monitored through front glass of the strong box using digital camera. Series of images were taken at fixed time interval for each test. Digital image analysis was performed on captured images to evaluate the movements in geogrid reinforced soil wall models at pre-failure and failure conditions. The post failure investigation was performed to assess the rupture points in the geogrid layers at failure of the geogrid reinforced soil wall models. Geogrid reinforced soil wall models were evaluated in terms of reinforcement strains and wall face movements. A significant reduction in wall face movements (upto $59.8 \%$ ) and peak strains (upto $42 \%$ ) were observed due to geofoam inclusion.
\end{abstract}

Keywords : Geofoam, geogrid, Image analysis, small-scale modeling, strip loading

\section{INTRODUCTION}

Soil reinforcement is a widely used technique to stabilize the soil structures. Different methods of evaluation and design as also established for reinforced soil for various types of reinforcement based on their rigidity and the response to several environmental factors(BS 8006 (2010), FHWA (2000)). Geogrid reinforcements are in wide use because of their advantages such as higher flexibility, enhanced workability, longer life, ability to take higher settlements and better frictional behavior with surrounding soil. A wide knowledge of deformation behavior of geogrid reinforced soil walls for various types of reinforcements, various types of soils and various types of loading is available as on date. Various studies have been made on geogrid reinforced soil walls through analytical and numerical methods (Leshchinsky\& Han (2007), Bathurst et al. (2008), Huang et al. (2009), Anderson et al. (2012), Liu (2013), Liu \& Won (2014)), small scale model tests (Juran\& Christopher (1989), Huang (2008), Sabermahani et al. (2009), Guler\&Selek (2014)), field studies (Bussert\&
Cavanaugh (2010), DiFiore \& Strohman (2012), Talebi et al (2014)) and centrifuge model tests ( Zornberg et al. (1998b), Viswanadham \& Mahajan (2007), Viswanadham \& K"onig (2009), Izawa \&Kuwano (2010)). However, majority of these studies are either related to the self-weight loading of the reinforced soil walls or the uniform surcharge over the reinforced zone and backfill. Very few studies report the behaviour of geogrid reinforced soil structures for a narrow strip loading placed over the reinforced zone or backfill (Sommers \& Viswanadham (2009)). The information regarding the behaviour of geogrid reinforced soil walls with EPS geofoam (compressible) inclusion is also very limited. Various researchers have reported the ability of the geofoam inclusion as a compressible inclusion, which was mainly related to the dynamic load attenuation (Horvath (1997), Zarnani\& Bathurst (2007), Bathurst et al. (2007), Hatami\&Witthoeft (2008), Horvath (2008), Trandafir A. \& B. (2010), Ertugrul \& Trandafir (2011), Dave \& Murty (2012), Ertugrul \& Trandafir (2013), Dave \& Dasaka (2014)). So, the behaviour of geogrid reinforced soil walls subjected to a strip loading and with a geofoam inclusion has not been reported yet. So, small-scale model tests on geogrid reinforced soil walls with geofoam inclusion and subjected to strip loading should provide a broad insight into this particular geotechnical problems and its solution. In accordance with above, present study demonstrates the small scale model tests on geogrid reinforced soil wall models subjected to a $0.23 \mathrm{H}$ (Height) wide strip loading over reinforced fill and backfill with and without geofoam inclusion. Reinforcement type, reinforcement length and reinforcement spacing was kept constant for all the model tests performed. Parameters varied were mainly as placement position of geofoam, geofoam density and geofoam thickness.

\section{MOTIVATION BEHIND PRESENT STUDY}

Figure 1 shows the schematic cross section of the geogrid reinforced soil wall with $0.23 \mathrm{H}$ wide (a) Footing at $0.5 \mathrm{Lr}$ (Length of reinforcement) from crest of the wall, (b) Footing at $1.78 \mathrm{Lr}$ from crest of the wall. Strip load applied at the top of the reinforced zone should induce the maximum strains in the top layer of the reinforcement, which would reduce further for the following reinforcements subsequently towards the foundation layer. When no compressible inclusion made behind reinforced zone, the applied load would transfer towards the face of the reinforced soil wall. This is mainly due to the fact that the only location that allows deformations is the face of the geogrid reinforced soil wall. Which results the wall face movements to be in direct proportion with the strip load settlement. Geofoam, when placed behind the reinforced zone 
should allow the deformations at the junction of the reinforced zone and geofoam panel. Depending on the compressibility of the geofoam inclusion the deformations would allow the reinforcements to develop friction with soil at the end of reinforcements. This may result in mobilization of the reinforcement strength at the face as well as at the end of the reinforced soil wall. So, the proportionality constant between wall face movements and footing settlement should reduce for geofoam inclusion case. At the same time, when footing is placed over backfill, a similar mechanism of geofoam compression would occur. The compression occurred in geofoam mobilizes the backfill shear strength resulting in lower earth pressure than the theoretical predictions for without geofoam case. This compression in geofoam also provides a wider distribution of the applied load. Amount of shift in the load distribution lines depends on the compressibility of the geofoam. Due to this shift the vertical stress at any point below the surface will be lower than the without geofoam case. Which ultimately would produce lower lateral earth pressure.

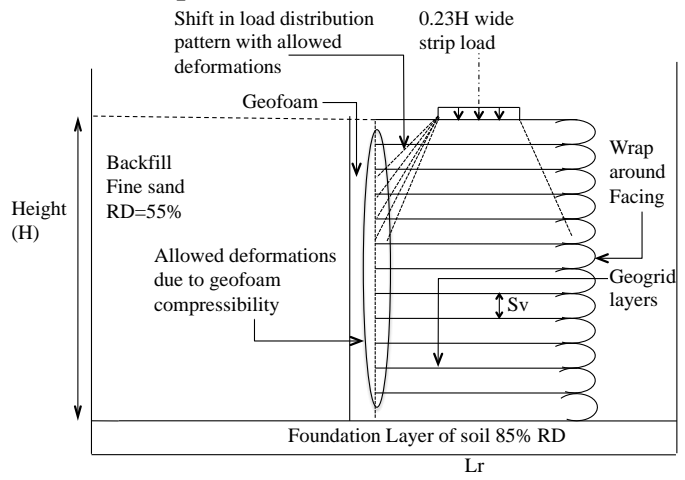

(a) Footing at $0.5 \mathrm{Lr}$

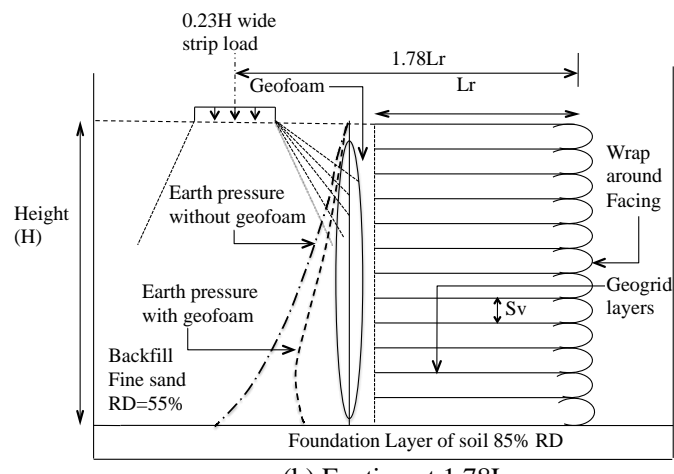

(b) Footing at $1.78 \mathrm{Lr}$

Fig. 1. Schematic cross section of geogrid reinforced soil wall with geofoam inclusion

\section{MODEL MATERIAL}

\section{A. Sand}

The sand used for this study was Bombay beach sand, composed of rounded and sub rounded particles. Sand was classified as Silty Sand (SM) in the unified soil classification system (USCS). The model sand was found to have internal frictional resistance of $32^{\circ}, 35^{\circ}$ and $38^{\circ}$ for $55 \%, 75 \%$ and $85 \%$ relative density respectively. Table 1 summarizes the properties of the model sand used in the present study. Figure 2(a) shows the photographic view of the model sand used in the present study. Properties of the model sand are summarized in table 1 .

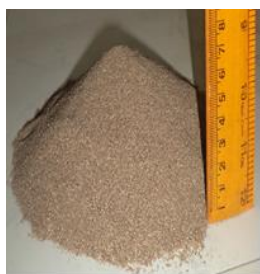

(a) Model sand

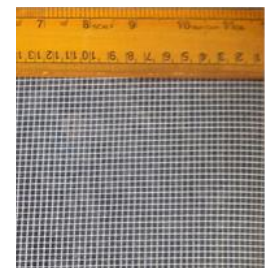

(b) Model geogrid

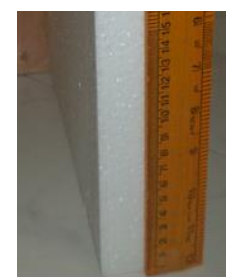

(c) Model geofoam
Fig. 2. Photographic view of model materials used in the present study

\section{B. Geogrid}

The geogrid selected for the present study was on the basis of their physical properties and the resemblance to the commercially available geogrids. Model geogrid selected in the present study was falling in the category of the high strength geogrids. The pattern and opening area and rib dimensions were chosen such that it resembles the prototype geogrids available in the industry. To ensure the identical frictional bond behavior, the percentage opening area was chosen to be in the bandwidth of upto $90 \%$ to that of the prototype geogrids. The wide width tensile strength of the geogrid was found to be $3.8 \mathrm{kN} / \mathrm{m}$ at an ultimate tensile strain of $24 \%$.

\section{Geofoam}

Expanded polystyrene (EPS) geofoam was used in the present study as a compressible inclusion behind reinforced zone. Three types of geofoam were used in the present study F1, F2 and F3 with varying density 8,16 and $24 \mathrm{~kg} / \mathrm{m}^{3}$ respectively. The compressive resistance in uniaxial

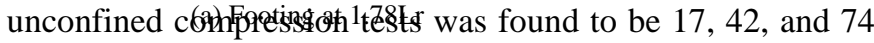
$\mathrm{kPa}$ for geofoam F1, F2 and F3 respectively. At the same time the elastic modulus was observed to be 850,2100 and $3700 \mathrm{kPa}$ for geofoam F1, F2 and F3 respectively. Figure 4 shows the uniaxial unconfined compressive stress strain variation for model geofoam used in the present study. Properties of the model geofoam are summarized in table I.

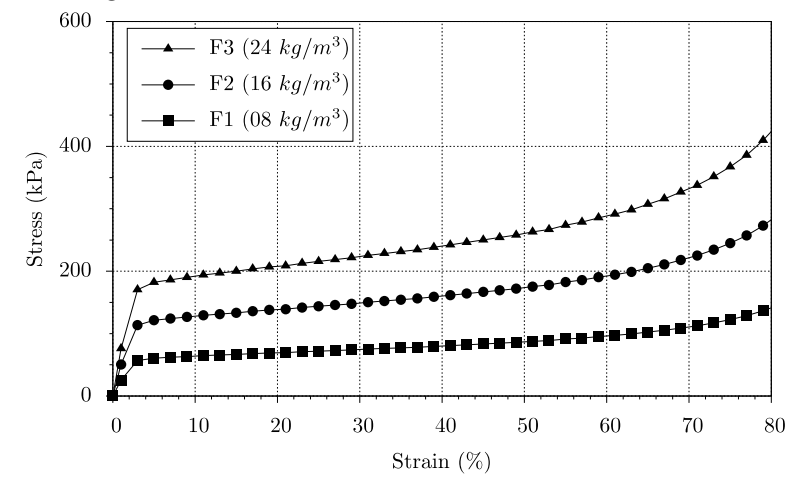

Fig. 4. Unconfined uniaxial stress strain behavior of model geofoam

TABLE I- PROPERTIES OF THE MODEL MATERIALS USED IN PRESENT STUDY

\begin{tabular}{|l|c|}
\hline Properties & Values \\
\hline Sand & 2.61 \\
\hline Specific Gravity $(\mathrm{G})$ & SM \\
\hline Soil classification (USCS) & 1.17 \\
\hline Coefficient of curvature $(\mathrm{Cc})$ & 1.99 \\
\hline Coefficient of uniformity $(\mathrm{Cu})$ & \\
\hline
\end{tabular}




\begin{tabular}{|c|c|c|c|}
\hline \multicolumn{3}{|l|}{ Maximum void ratio $\left(\theta_{\max }\right)$} & 0.943 \\
\hline \multicolumn{3}{|c|}{ Minimum void ratio $\left(\theta_{\min }\right)$} & 0.691 \\
\hline \multicolumn{3}{|c|}{ Unit weight of soil at $55 \%$ relative density $\left(\mathrm{Kg} / \mathrm{m}^{\mathrm{a}}\right)$} & 1446.7 \\
\hline \multicolumn{3}{|c|}{ Unit weight of soil at $85 \%$ relative density $\left(\mathrm{Kg} / \mathrm{m}^{\mathrm{a}}\right)$} & 1510.41 \\
\hline \multicolumn{3}{|c|}{ Angle of internal friction at $55 \%$ relative density $\left({ }^{\circ}\right)$} & $32^{\circ}$ \\
\hline \multicolumn{3}{|c|}{ Angle of internal friction at $55 \%$ relative density $\left({ }^{\circ}\right)$} & $38^{\circ}$ \\
\hline \multicolumn{4}{|c|}{ Geogrid } \\
\hline $\begin{array}{l}\text { Ultimate tensile load, } \mathrm{T}_{\text {ult }} \\
(\mathrm{kN} / \mathrm{m})\end{array}$ & \multicolumn{3}{|c|}{3.8} \\
\hline $\begin{array}{l}\text { Ultimate tensile strain, } \varepsilon_{\text {ult }} \\
(\%)\end{array}$ & \multicolumn{3}{|c|}{24} \\
\hline \multicolumn{4}{|l|}{ Geofoam } \\
\hline Geofoam type & $\begin{array}{l}\text { Expanded } \\
\text { polystyrene }\end{array}$ & $\begin{array}{l}\text { Expanded } \\
\text { polystyrene }\end{array}$ & $\begin{array}{l}\text { Expanded } \\
\text { polystyrene }\end{array}$ \\
\hline Geofoam legend & $\mathrm{F} 1$ & $\mathrm{~F} 2$ & F3 \\
\hline Density $\left(\mathrm{kg} / \mathrm{m}^{3}\right)$ & 8 & 16 & 24 \\
\hline $\begin{array}{l}\text { Compressive resistance at } \\
2 \% \text { strain }(\mathrm{kPa})\end{array}$ & 17 & 42 & 74 \\
\hline $\begin{array}{l}\text { Compressive elastic } \\
\text { modulus }\left(\mathrm{kN} / \mathrm{m}^{2}\right)\end{array}$ & 850 & 2100 & 3700 \\
\hline
\end{tabular}

\section{METHODOLOGY}

Figure 5 shows the front view of the geogrid reinforced soil wall model constructed without and with geofoam inclusion. A custom designed and developed strong steel box fabrication was used for small-scale tests on geogrid reinforced soil wall models. This strong box consists of a $15 \mathrm{~mm}$ thick steel panel from four sides i.e. bottom, back, and side panels. The front panel was made up of a $18 \mathrm{~mm}$ thick glass panel to facilitate the two dimensional view of the model. Movements occurring in the geogrid reinforced soil wall models were captured with the help of a digital camera at a fixed time interval through this transparent front glass panel.

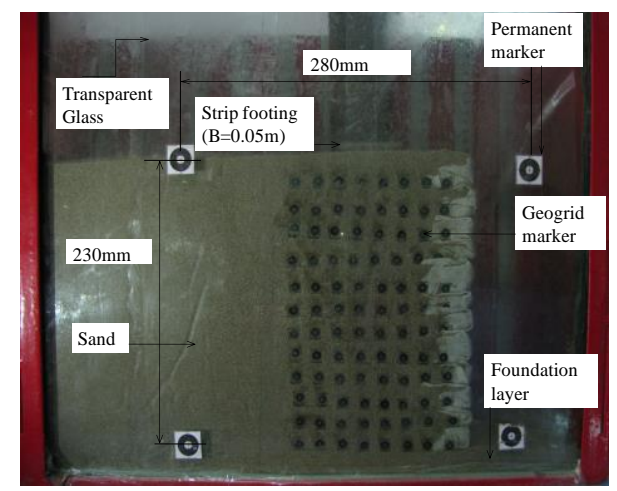

(a) Without geofoam

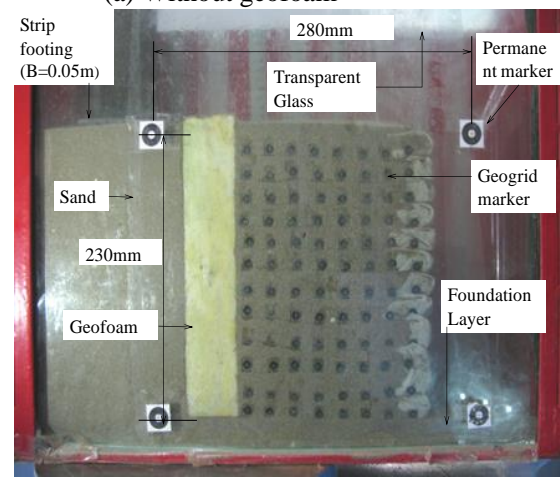

(b) With geofoam

Fig. 5. Front view of the model
The strong box was proof tested for its capacity before beginning of the tests for different soil backfills and different loading intensities. No deformations were observed to occur in the steel panels of the strong box till the loading intensity reaches upto the $55 \mathrm{kN}$. However, as the vertical load reaches $55 \mathrm{kN}$ (characteristic value for $95 \%$ successful cases) the front glass panel was observed to break catastrophically. Numbers of thin polythene sheet strips were placed inside the strong box after application of grease layer. Polythene strips were placed such that those moves along with the soil during the test and no boundary friction occur during the test.To ensure a firm foundation conditions and the failure does not pass through the foundation layer, sand with relative density $85 \%$ was placed for bottom foundation layer of $30 \mathrm{~mm}$ thickness. Reinforced fill and backfill was placed at the relative density of $55 \%$ consistently with the help of sand pluviation technique for all the tests performed. During the construction of reinforced soil, a wooden formwork was placed at the rightmost corner of the strong box. Wooden formwork ensures the aligned construction of the reinforced soil wall at $90^{\circ}$ to the horizontal and avoids any deformations during the construction process. Four permanent markers were glued to the glass panel so as to provide a benchmark to measure movements of the geogrid markers during the progress of the tests. 'L' shaped plastic markers were glued to the geogrid layers to monitor the movements during the tests with the help of image analysis.A thin geotextile was used at the wrapped face of each layer so as to avoid any sand leakage through geogrid openings. Digital camera was fixed on a PVC stand arrangement to facilitate the undistorted monitoring of the geogrid reinforced soil wall models. Two sets of lithium battery operated LED lighting panels were used to maintain a constant intensity of illumination throughout the progress of the test. A constant height of $0.24 \mathrm{~m}$ was maintained for all the geogrid reinforced soil wall models tested in this study. Reinforcement length of $0.7 \mathrm{H}$ and reinforcement spacing of $0.083 \mathrm{H}$ was adopted for all the reinforced soil wall models. Three different geofoam types were used in the present study, which were placed behind the reinforced zone with varying thickness and density under the particular test legend.

\section{MODEL TEST PROCEDURE}

All the geogrid reinforced soil wall models were tested under a UTM (Universal Testing Machine) at DIEMS Aurangabad with a maximum compressive and tensile capacity of $1000 \mathrm{kN}$. Formwork was kept in its position till the desired location of the strong box is identified and fixed for the testing. A $0.023 \mathrm{H}$ wide footing was placed at the center of the reinforced zone $(0.5 \mathrm{Lr}$ from the crest of the wall) for first series of tests followed by at the center of the backfill (1.78Lr from the crest of the wall) for second series of the tests. A gradual vertical load was applied at a constant strain rate of $5 \mathrm{~mm} / \mathrm{min}$ till the maximum settlement of $30 \mathrm{~mm}$ reaches or the maximum load of $35 \mathrm{kN}$ reaches (whichever occurs earlier). Images were taken at a constant time interval with the help of a digital camera (Canon make, 9 megapixel, enhanced shutter speed). Images taken were stored in a connected computer located a few meters away from the test setup. 


\section{TEST PROGRAM}

TABLE II- DETAILS OF THE MODEL TESTS PERFORMED IN THE

\begin{tabular}{|c|c|c|c|}
\hline $\begin{array}{l}\text { Test } \\
\text { legend }\end{array}$ & $\begin{array}{l}\text { Geofoam } \\
\text { thickness } \\
\text { (mm) }\end{array}$ & $\begin{array}{c}\text { Geofoam } \\
\text { density }\left(\mathrm{kg} / \mathrm{m}^{3}\right)\end{array}$ & $\begin{array}{c}\text { Footing } \\
\text { Location from } \\
\text { crest of the wall }\end{array}$ \\
\hline RSWS01 & $*$ N.A & *N.A & \multirow{10}{*}{$0.5 \mathrm{~L}_{\mathrm{r}}$} \\
\hline RSWS02 & 10 & \multirow{3}{*}{8} & \\
\hline RSWS03 & 20 & & \\
\hline RSWS04 & 50 & & \\
\hline RSWS05 & 10 & \multirow{3}{*}{16} & \\
\hline RSWS06 & 20 & & \\
\hline RSWS07 & 50 & & \\
\hline RSWS08 & 10 & \multirow{3}{*}{24} & \\
\hline RSWS09 & 20 & & \\
\hline RSWS10 & 50 & & \\
\hline RSWS11 & *N.A & $*$ N.A & \multirow{10}{*}{$1.78 \mathrm{~L}_{\mathrm{r}}$} \\
\hline RSWS12 & 10 & \multirow{3}{*}{8} & \\
\hline RSWS13 & 20 & & \\
\hline RSWS14 & 50 & & \\
\hline RSWS15 & 10 & \multirow{3}{*}{16} & \\
\hline RSWS16 & 20 & & \\
\hline RSWS17 & 50 & & \\
\hline RSWS18 & 10 & \multirow{3}{*}{24} & \\
\hline RSWS19 & 20 & & \\
\hline RSWS20 & 50 & & \\
\hline
\end{tabular}

Table II shows the details of the model tests performed in the present study. Total 20 model tests were performed with and without geofoam inclusion behind the reinforced zone. Model RSWS01 and RSWS11 were tested without any geofoam inclusion and were treated as the base models for evaluation of the efficiency of the geofoam behind reinforced zone.

\section{ANALYSIS AND INTERPRITATION}

\section{A. Image Analysis}

Image analysis was performed on the images obtained from the tests performed with the help of ImageJ open source software. The displacements occurred in geogrid reinforced soil wall models were depicted using the advanced template matching plugins and PIV (Particle Image Velocimetry) analysis. Figure 6 shows the deformed profile of geogrid reinforced soil wall models with and without geofoam for strip loading over reinforced zone and over backfill respectively.

Figure 7 shows the displacement vector diagrams for geogrid reinforced soil walls without and with geofoam when footing is placed over the reinforced zone. Comparison is made between two identical models with and without geofoam at a maximum footing settlement of $15 \mathrm{~mm}$ (i.e. $\mathrm{S}_{\mathrm{f}} / \mathrm{B}=0.6$ ). Vectors in the figure are scaled up two times than the original for better visualization of the results. It can be clearly observed that for geogrid reinforced soil wall without geofoam inclusion majority of the deformations are occurring towards the face of the geogrid reinforced soil wall. A top portion of the soil exactly behind the reinforced zone was also observed to shift upward confirming the Terzhaghi's conventional general shear failure theory of shallow foundations.

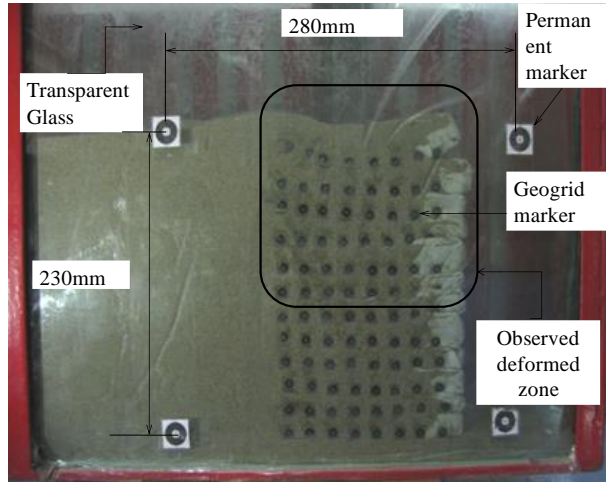

(a) Without geofoam, footing at $0.5 \mathrm{Lr}$

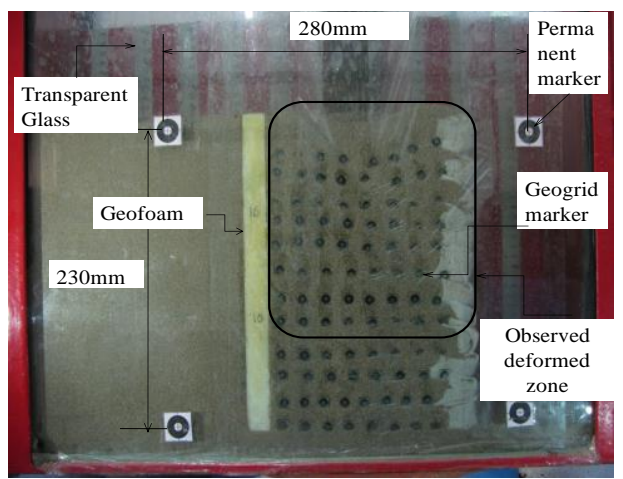

(a) With geofoam, footing at $0.5 \mathrm{Lr}$

Fig.6. Deformed profile of geogrid reinforced soil wall models

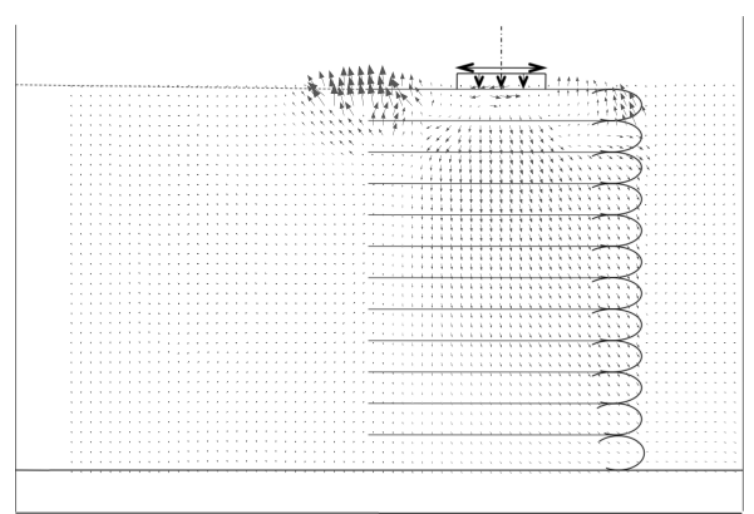

(a) Without geofoam, footing at $0.5 \mathrm{Lr}$

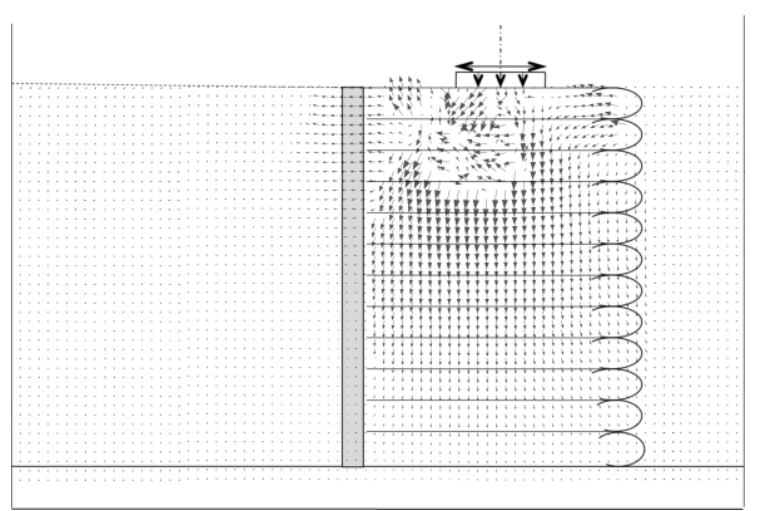

(b) With geofoam, footing at $0.5 \mathrm{Lr}$

Fig.7. Displacement vectors diagram for geogrid reinforced soil wall models 
When geofoam is placed behind reinforced zone the reinforced soil mass is allowed to move towards the backfill, which causes the frictional bond development between geogrid and the surrounding soil. Due to this the wall face movements gets reduced for an identical settlement of the footing in geofoam inclusion cases than that of the without geofoam case.

\section{B. Wall Face Moments}

Wall face movements of geogrid reinforced soil wall models were evaluated through image analysis for various cases with varying density and thickness of the geofoam. Figure 8 shows the variation of normalized wall face movements with normalized height. Wall face movements were observed to be significantly higher at top middle third of the height of the wall when footing was placed over the reinforced zone. This is mainly due to the fact that, the tensile resistance in the reinforcements gets developed with settlement of footing. Topmost geogrid layer was observed to get hold and pulled back towards the footing, which is mainly due to the fact that the anchorage length of the geogrid of top layers falls below the corners of footing and thus restrict the lateral movement of the crest of the wall. This should not be the case when a rigid panel facing is used for construction of the geogrid reinforced soil walls. Geofoam inclusion behind reinforced zone does not change the pattern of wall face movements significantly, but shows a significant decrease in wall face movements with increase in thickness as well as decrease in density of the geofoam. This is mainly due to the allowed deformation of reinforced soil towards the backfill. At the same time when footing is placed over the backfill, lateral earth pressure increases on the reinforced soil with settlement of footing. This lateral earth pressure mainly affects the upper half portion of the reinforced soil wall showing translational outward movements in direct sliding. Geofoam panel placed behind the reinforced zone allows the movements in backfill soil resulting in shear strength mobilization of the backfill soil. This facilitates the absorption of the deformations due to footing settlements in terms of geofoam compression and reduced lateral earth pressure due to shear strength mobilization. Also, the geofoam panel acts as a cushion behind reinforced zone and distributes the load evenly on the reinforced soil. Due to which the wall face movements tends to be similar over the elevation of the reinforced soil wall.

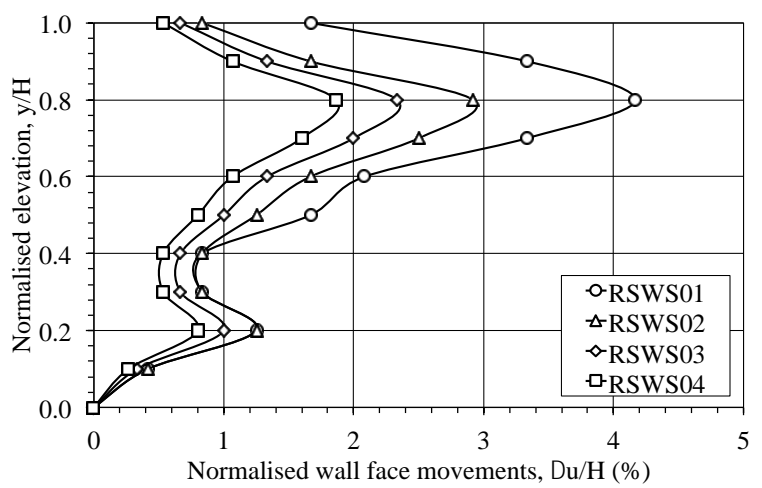

(a) Footing at $0.5 \mathrm{Lr}$

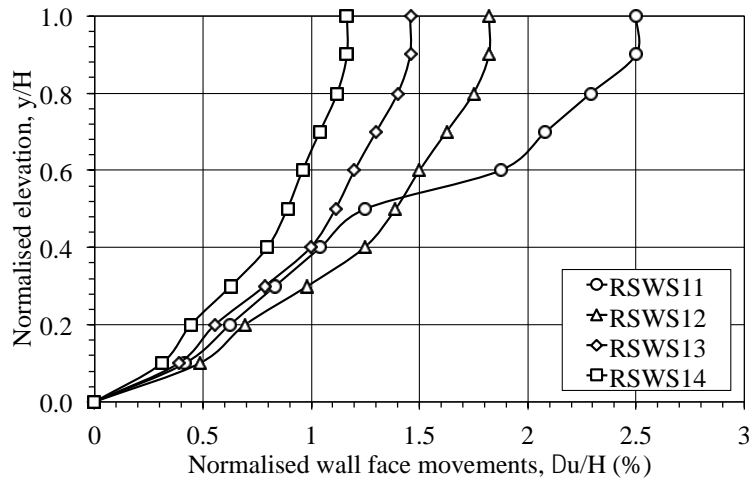

(b) Footing at $1.78 \mathrm{Lr}$

Fig. 8. Variation of wall face movements along the height of geogrid reinforced soil walls

\section{Reinforcement Strain Distribution}

Figure 9 shows the reinforcement strain distribution within the geogrid reinforced soil walls without and with geofoam inclusion and footing placed above the reinforced zone. Peak strains were observed to be located towards the face of the wall following a definite pattern of line of action. The line of action of stress distribution was observed to be deflecting outward along the height of the reinforced soil wall. A maximum peak strain was observed to be up to $24 \%$ for top layer of the geogrid reinforced soil wall without geofoam inclusion. Maximum peak strain is nothing but the maximum of the peak strains obtained for each reinforcement layer. When geofoam inclusion is made behind reinforced zone, peak strains were observed to be shifting towards the center of the reinforcement layer. The peak strains were observed to reduce significantly with geofoam inclusion. Also, the line of action of the load distribution was found to be extending outward, which indicates a wider load bearing area and thus the lesser peak strains. This is mainly due to the fact that the allowed deformations at both the ends of reinforced zone distribute the load evenly within the reinforcements and the strength mobilization at both the ends helps deflecting the load distribution line outward. Reinforcement peak strains were of least concern when footing was placed over the backfill region. This is mainly because the main cause of failure was observed to be the translational movements of the reinforced beds and thus not reported in this study.

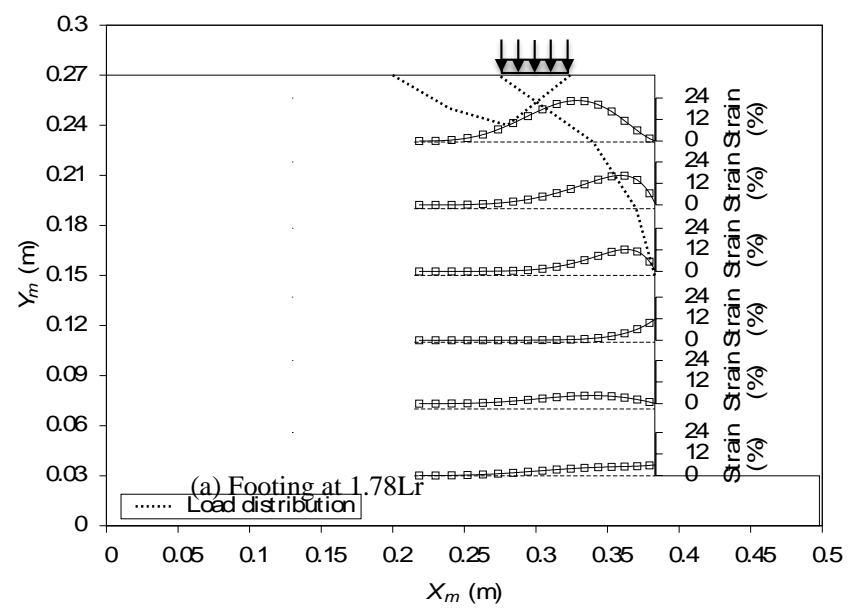

(a) Without geofoam 


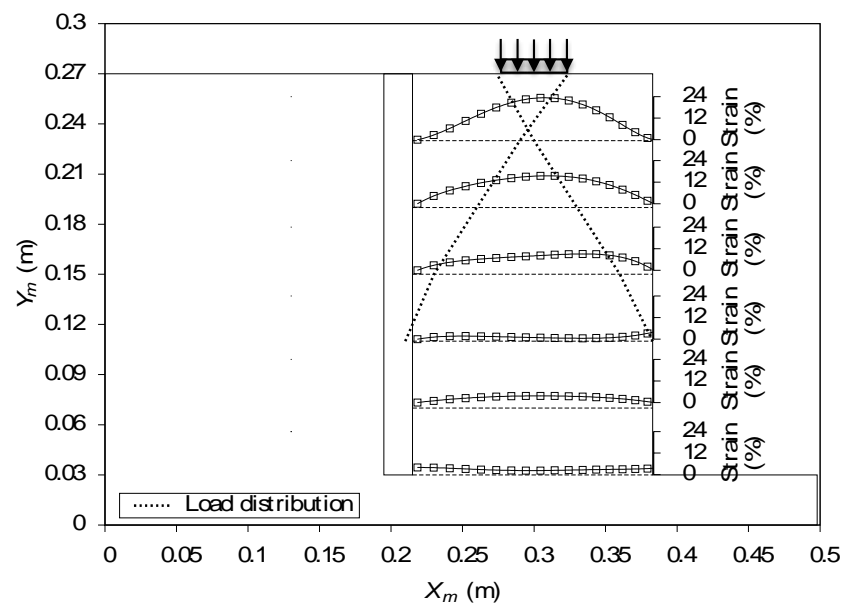

(b) With geofoam

Fig. 9.Variation of wall face movements along the height of geogrid reinforced soil walls

\section{RESULT AND DISCUSSION}

Geofoam density was found to have significant influence on enhancement of deformation behavior of geogrid reinforced soil walls. Lower the density higher the allowed deformations towards backfill. So, the lower density geofoam provided higher efficiency in performance enhancement of geogrid reinforced soil walls. Figure 10 shows the variation in wall face movements with increase in geofoam thickness for various densities of the geofoam used in this study. Wall face movements were observed to decrease significantly with geofoam inclusion and the decrease in wall face movements was found to be higher for low density geofoam. A maximum decrease of up to $59.8 \%$ was observed for footing placed above the reinforced zone when $50 \mathrm{~mm}$ thick low density geofoam (F1) inclusion was made. At the same time this decrease was found to be higher up to $72 \%$ when footing was placed above the backfill. A similar trend of decrease was observed in reinforcement peak strains. Table 3 summarizes the results obtained through test series performed in the present study.

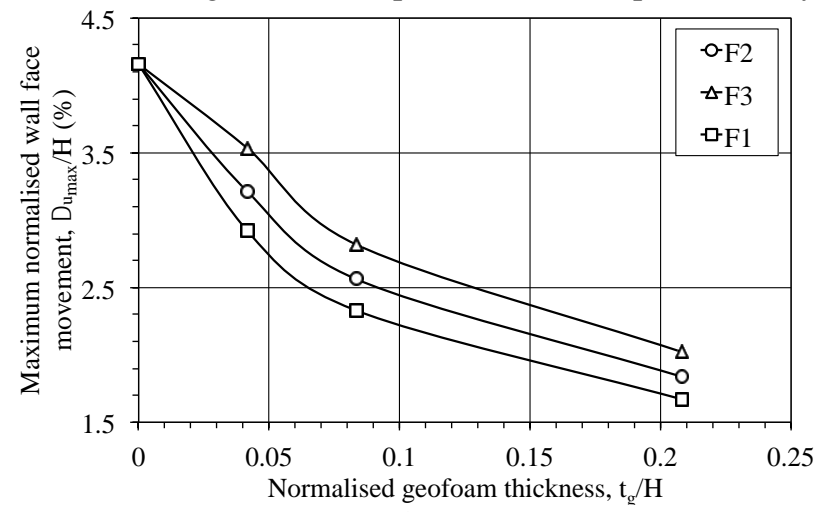

(a) Footing at $0.5 \mathrm{Lr}$

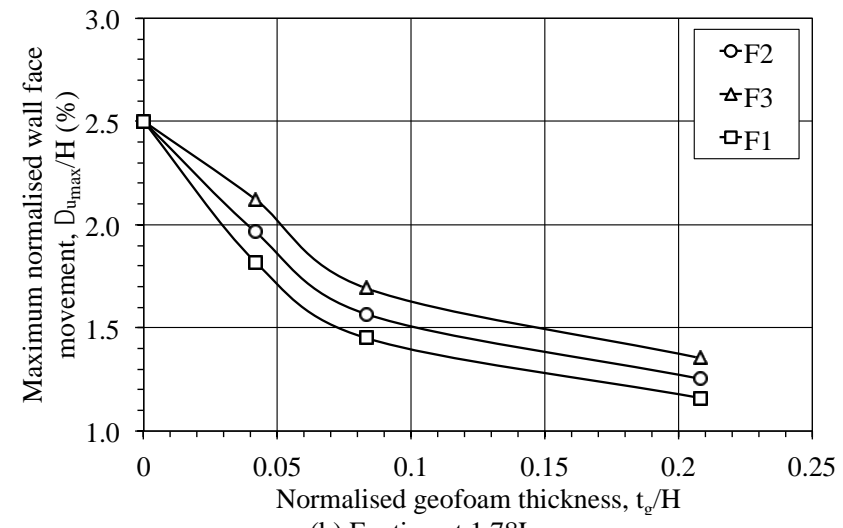

(b) Footing at $1.78 \mathrm{Lr}$

Fig.10.Variation of wall face movements along the height of geogrid reinforced soil walls

\section{CONCLUSION}

Based on the observations made in the present study, Conclusions made are as below,

1. Geofoam as a compressible inclusion provides significant enhancements in performance of the geogrid reinforced soil wall when subjected to a vertical strip loading.

2. Wall face movements of geogrid reinforced soil walls decreases with placement of geofoam behind reinforced zone irrespective of the location of the strip loading applied. However the geofoam performs better when strip loading is subjected over the backfill soil. A maximum decrease in wall face movements for low density $50 \mathrm{~mm}$ thick geofoam was observed to be upto $59.8 \%$.

3. Performance enhancement of geogrid reinforced soil walls due to geofoam inclusion is directly proportional to the geofoam thickness and inversely proportional to the geofoam density.

4. When geofoam placed behind reinforced zone and strip loading is applied over the reinforced zone, the reinforcement strain gets distributed over the length of the reinforcement, which ultimately facilitates the reduced peak strain at a particular location in a geogrid layer. Which ultimately results in increase in safety of the geogrid reinforced soil walls. 
TABLE III- SUMMARY OF THE MODEL TESTS PERFORMED IN THE PRESENT STUDY

\begin{tabular}{|c|c|c|c|c|c|c|c|}
\hline Test legend & $\begin{array}{c}\text { Geofoam } \\
\text { thickness } \\
(\mathbf{m m})\end{array}$ & $\begin{array}{c}\text { Geofoam } \\
\text { density } \\
(\mathrm{kg} / \mathrm{m3})\end{array}$ & $\begin{array}{c}\text { Footing Location } \\
\text { from crest of the } \\
\text { wall }\end{array}$ & $\begin{array}{c}\text { Maximum wall } \\
\text { face movement } \\
(\text { Dumax/H)\% }\end{array}$ & $\begin{array}{c}\text { Maximum } \\
\text { peak strain } \\
(\%)\end{array}$ & $\begin{array}{l}\text { \% Reduction in } \\
\text { (Dumax/H) }\end{array}$ & $\begin{array}{c}\text { \% Reduction in peak } \\
\text { strain }\end{array}$ \\
\hline RSWS01 & $*$ N.A & $*$ N.A & \multirow{10}{*}{$0.5 \mathrm{Lr}$} & 4.16 & 24 & $*$ N.A & $*$ N.A \\
\hline RSWS02 & 10 & \multirow{3}{*}{8} & & 2.92 & 19.00 & 29.81 & 20.83 \\
\hline RSWS03 & 20 & & & 2.33 & 16.00 & 43.99 & 33.33 \\
\hline RSWS04 & 50 & & & 1.67 & 14.00 & 59.86 & 41.67 \\
\hline RSWS05 & 10 & \multirow{3}{*}{16} & & 3.21 & 20.90 & 22.79 & 12.92 \\
\hline RSWS06 & 20 & & & 2.56 & 17.60 & 38.39 & 26.67 \\
\hline RSWS07 & 50 & & & 1.84 & 15.40 & 55.84 & 35.83 \\
\hline RSWS08 & 10 & \multirow{3}{*}{24} & & 3.53 & 22.99 & 15.07 & 4.21 \\
\hline RSWS09 & 20 & & & 2.82 & 19.36 & 32.23 & 19.33 \\
\hline RSWS10 & 50 & & & 2.02 & 16.94 & 51.43 & 29.42 \\
\hline RSWS11 & $*$ N.A & $*$ N.A & \multirow{10}{*}{$1.78 \mathrm{Lr}$} & 2.5 & \multirow{10}{*}{ \#N.A } & $*$ N.A & \multirow{10}{*}{ \#N.A } \\
\hline RSWS12 & 10 & \multirow{3}{*}{8} & & 1.82 & & 56.25 & \\
\hline RSWS13 & 20 & & & 1.45 & & 65.14 & \\
\hline RSWS14 & 50 & & & 1.16 & & 72.12 & \\
\hline RSWS15 & 10 & \multirow{3}{*}{16} & & 1.96 & & 52.75 & \\
\hline RSWS16 & 20 & & & 1.56 & & 62.36 & \\
\hline RSWS17 & 50 & & & 1.25 & & 69.88 & \\
\hline RSWS18 & 10 & \multirow{3}{*}{24} & & 2.12 & & 48.97 & \\
\hline RSWS19 & 20 & & & 1.69 & & 59.34 & \\
\hline RSWS20 & 50 & & & 1.35 & & 67.48 & \\
\hline
\end{tabular}

*Not applicable as test was performed without geofoam inclusion

\#Not applicable as not presented in this study

\section{REFERENCES}

[1] Allen, T., Bathurst, R., Holtz, R., Lee, W. \& Walters, D. (2004), 'New Method for Prediction of Loads in Steel Reinforced Soil Walls', Journal of Geotechnical and Geoenvironmental Engineering 130(11), $1109-1120$.

[2] Anderson, P., Gladstone, R. \&Sankey, J. (2012), State of the Practice of MSE Wall Design for Highway Structures, in 'Geotechnical Engineering State of the Art and Practice: Keynote Lectures from GeoCongress 2012', 1, Oakland, California, United States, pp. 443-463.

[3] Bathurst, R. J., Miyata, Y., Nernheim, A., Allen, A. M. \& Miyata, Y. (2008), 'Refinement of K-stiffness Method for geosyntheticreinforced soil walls', Geosynthetics International 15(4), 269-295.

[4] Bathurst, R. J., Zarnani, S. \& Gaskin, A. (2007), 'Shaking table testing of geofoam seismic buffers', Soil Dynamics and Earthquake Engineering 27(4), 324-332.

[5] BS 8006 (2010), Code of practice for strengthened /reinforced soils and other fills, British Standard Institute (BSI), London, UK.

[6] Bussert, F. \& Cavanaugh, J. (2010), Recent Research and Future Implications of the Actual Behavior of Geogrids in Reinforced Soil, in 'Earth Retention Conference 3', 1, Bellevue, Washington, United States, pp. 460-477.

[7] Dave, T. \&Dasaka, S. (2014), Surcharge Induced Earth Pressure Reduction on Rigid Retaining wall using EPS Geofoam, in 'Tunneling and Underground Construction', 1, Shanghai, China, pp. 836-844.

[8] DiFiore, S. \&Strohman, B. (2012), Look Out Below! Potential Pitfalls and Suggested Improvements in the Design and Construction of Mechanically Stabilized Earth (MSE) Walls, in 'Forensic Engineering 2012: Gateway to a Safer Tomorrow', 1, San Francisco, California, United States, pp. 641-650.

[9] Ertugrul, O. \&Trandafir, A. (2011), 'Reduction of Lateral Earth Forces Acting on Rigid Nonyielding Retaining Walls by EPS Geofoam Inclusions', Journal of Materials in Civil Engineering 23(12), 1711-1718
[10] FHWA (2000), Mechanically Stabilized Earth Walls and Reinforced Soil Slopes Design and Construction Guidelines, 00 edn, FHWA, Washington DC, United States.

[11] Guler, E. \&Selek, O. (2014), 'Reduced-Scale Shaking Table Tests on Geosynthetic- Reinforced Soil Walls with Modular Facing', Journal of Geotechnical and Geoenvironmental Engineering 140(6), 1-11.

[12] Hatami, K. \&Witthoeft, A. F. (2008), 'A numerical study on the use of geofoam to increase the external stability of reinforced soil walls', Geosynthetics International 15(6), 452-470.

[13] Horvath, J. (1997), 'The Compressible Inclusion Function of EPS Geofoam', Geotextiles and Geomembranes 15(1-3), 77-120.

[14] Horvath, J. (2008), Extended Veletsos-Younan Model for Geofoam Compressible Inclusions Behind Rigid, Non-Yielding EarthRetaining Structures, in 'Geotechnical Earthquake Engineering and Soil Dynamics IV', 1, Sacramento, California, United States, pp. $1-10$.

[15] Huang, B., Bathurst, R. J. \&Hatami, K. (2009), 'Numerical study of reinforced soil segmental walls using three different constitutive soil models', Journal of Geotechnical and Geoenvironmental Engineering, ASCE 135(10), 1486-1498.Huang, C. C. (2008), 'Comparative study on performance and index tests simulating abrasion damage of a woven geotextile',

[16] Lee, K. Z. Z., Jonathan, T. \& Wu, M. (2004), 'A synthesis of case histories on GRS bridge-supporting structures with flexible facing', Geotextiles and Geomembranes 22(4), 181-204.

[17] Leshchinsky, D. \& Han, J. (2007), Analytical Framework for Geosynthetic Reinforced Earth Structures: Part I - Ideal Approach, in 'Geosynthetics in Reinforcement and Hydraulic Applications', 1, Denver, Colorado, United States, pp. 1-9.

[18] Liu, H. (2013), An Analytical Method for Reinforcement Load of Wrapped-Face Mse Walls before Full Mobilization of Soil Strength, in 'Geo-Congress 2013: Stability and Performance of Slopes and Embankments III', 1, San Diego, California,

[19] United States, pp. 519-528.Liu, H. \& Won, M. (2014), 'Stress Dilatancy and Reinforcement Load of Vertical-Reinforced Soil Composite: Analytical Method', Journal of Engineering Mechanics 140(3), 630-639. 
[20] Sabermahani, M., Ghalandarzadeh, A. \&Fakher, A. (2009), 'Experimental study on seismic deformation modes of reinforced- soil walls', Geotextiles and Geomembranes 27(2), 121-136.

[21] Shahgholi, M., Fakher, A. \& Jones, C. J. F. P. (2001), 'Horizontal slice method of analysis', Geotechnique 51(10), 881-885.Sommers, A. N. \&Viswanadham, B. V. S. (2009), 'Centrifuge model tests on the behavior of strip footing on geotextile reinforced slopes', Geotextiles and Geomembranes 27(6), 497-505.

[22] Talebi, M., Meehan, C., Cacciola, D. \& Becker, M. (2014), Design and Construction of a Geosynthetic Reinforced Soil Integrated Bridge System, in 'Geo-Congress 2014 Technical Papers: Geo-Characterization and Modeling for Sustainability', 1, Atlanta, Georgia, pp. 4176-4190.

[23] Viswanadham, B. V. S. \&Mahajan, R. (2004), 'Modeling of geotextile reinforced highway slopes in a geotechnical centrifuge', Geotechnical Special Publication, ASCE 126(1), 637-646.

[24] Viswanadham, B. V. S. \&Mahajan, R. R. (2007), 'Centrifuge model tests on geotextile-reinforced slopes', Geosynthetics International 14(6), 365-379.

[25] Yang, G., Zhang, B., Peng, L. \& Zhou, Q. (2009), 'Behaviour of geogrid reinforced soil retaining wall with concrete-rigid facing', Geotextiles and Geomembranes 27(5), 350-356.

[26] Yoo, C. (2004), 'Performance of a 6-year-old geosynthetic reinforced segmental retaining wall', Geotextiles and Geomembranes 22(5), 377-397.

[27] Zornberg, J. G., Mitchell, J. K. \& Sitar, N. (1997), 'Testing of Reinforced Slopes in a Geotechnical Centrifuge', Geotechnical Testing Journal, ASTM 20(4), 470-480.

[28] Zornberg, J. G., Sitar, N. \& Mitchell, J. K. (1998a), 'Performance of geosynthetic reinforced slopes at failure', Journal of Geotechnical and Geoenvironmental Engineering, ASCE 124(8), 670-683. 